\title{
Effects of galectin-9 on apoptosis, cell cycle and autophagy in human esophageal adenocarcinoma cells
}

\author{
EMIKO AKASHI $^{1}$, SHINTARO FUJIHARA ${ }^{1}$, ASAHIRO MORISHITA ${ }^{1}$, TOMOKO TADOKORO ${ }^{1}$, \\ TAIGA CHIYO $^{1}$, KEIKO FUJIKAWA ${ }^{1}$, HIDEKI KOBARA ${ }^{1}$, HIROHITO MORI ${ }^{1}$, HISAKAZU IWAMA ${ }^{2}$, \\ KEIICHI OKANO ${ }^{3}$, YASUYUKI SUZUKI ${ }^{3}$, TOSHIRO NIKI ${ }^{4}$, MITSUOMI HIRASHIMA $^{4}$ and TSUTOMU MASAKI ${ }^{1}$ \\ ${ }^{1}$ Department of Gastroenterology and Neurology, ${ }^{2}$ Life Science Research Center, and ${ }^{3}$ Gastroenterological Surgery and \\ ${ }^{4}$ Immunology and Immunopathology, Faculty of Medicine, Kagawa University, Kita-gun, Kagawa 761-0793, Japan
}

Received September 21, 2016; Accepted May 22, 2017

DOI: $10.3892 /$ or.2017.5689

\begin{abstract}
The incidence of esophageal adenocarcinoma (EAC) is rapidly increasing in western countries. The overall mortality of this disease remains high with a 5-year survival rate of less than $20 \%$, despite remarkable advances in the care of patients with EAC. Galectin-9 (Gal-9) is a tandemrepeat type galectin that exerts anti-proliferative effects on various cancer cell types. The aim of the present study was to evaluate the effects of Gal-9 on human EAC cells and to assess the expression of microRNAs (miRNAs) associated with the antitumor effects of Gal-9 in vitro. Gal-9 suppressed the proliferation of the EAC cell lines OE19, OE33, SK-GT4, and OACM 5.1C. Additionally, Gal-9 treatment induced apoptosis and increased the expression levels of caspase-cleaved cytokeratin 18, activated caspase- 3 and activated caspase- 9 . However, it did not promote cell cycle arrest by reducing cell cycle-related protein levels. Furthermore, Gal-9 increased the level of the angiogenesis-related protein interleukin-8 (IL-8) and markedly altered miRNA expression. Based on these findings, Gal-9 may be of clinical use for the treatment of EAC.
\end{abstract}

\section{Introduction}

Esophageal carcinoma is the sixth most common type of cancer worldwide and has remained an aggressive cancer because it is commonly diagnosed at later stages (1). Esophageal

Correspondence to: Professor Tsutomu Masaki, Department of Gastroenterology and Neurology, Faculty of Medicine/Graduate School of Medicine, Kagawa University, 1750-1 Ikenobe, Miki-cho, Kita-gun, Kagawa 761-0793, Japan

E-mail: tmasaki@med.kagawa-u.ac.jp

Abbreviations: Gal-9, galectin-9; EAC, esophageal adenocarcinoma; CRDs, carbohydrate recognition domains; miRNAs, microRNAs; CCK-8, Cell Counting kit-8; IL-8, interleukin-8; phospho-RTKs, phosphorylated receptor tyrosine kinases; CCK18, caspase-cleaved cytokeratin 18

Key words: esophageal adenocarcinoma, galectin-9, apoptosis, microRNAs, angiogenesis carcinoma is divided into two major types [squamous cell carcinoma (SCC) and adenocarcinoma], and the incidence of esophageal adenocarcinoma (EAC) is rapidly increasing in Western countries (2). The overall mortality of this disease remains high with a 5-year survival rate of less than $20 \%$, despite remarkable advances in the care of patients with EAC (3). A poor prognosis has been associated with diagnosis at an advanced stage and metastasis $(4,5)$.

Galectin-9 (Gal-9) is a tandem-repeat type galectin with two carbohydrate recognition domains (CRDs); it was first identified as an eosinophil chemoattractant and activation factor (6-8). Similar to other galectins, Gal-9 regulates various cellular functions in eosinophils, including cell aggregation, adhesion and apoptosis (9,10). Gal-9 also enhances antitumor immunity by initiating CRD-independent dendritic cell maturation and Th1-mediated antitumor immunity (11). Treatment with recombinant Gal-9 prolonged survival in a murine melanoma model by increasing the number of $\mathrm{CD}^{+}$cytotoxic T cells (CTLs), natural killer (NK) cells and macrophages (12). Furthermore, the Gal-9 receptor $\mathrm{T}$ cell immunoglobulin mucin-3 (Tim-3) negatively regulated $\mathrm{T}$ cell responses by promoting $\mathrm{CD}^{+} \mathrm{T}$ cell exhaustion and inducing the expansion of myeloid-derived suppressor cells $(13,14)$.

Recombinant Gal-9 induces dose-dependent apoptosis in various leukemic $\mathrm{T}$ cell lines in the presence of a functional CRD (15,16). Additionally, Gal-9 inhibits the growth of myeloma (17), chronic myeloid leukemia (18) and human melanoma both in vitro and in vivo $(19,20)$. Moreover, we have recently reported that recombinant Gal-9 exerts antitumor effects on various solid malignancies by affecting the phosphorylation of various proteins, angiogenesis and the expression of microRNAs (miRNAs) (21-23).

However, little is known about the antitumor effects of Gal-9 on EAC cells or the miRNAs associated with these effects. Therefore, the present study evaluated the effects of Gal-9 on the growth of EAC cell lines, the mechanism of action and the miRNAs associated with its antitumor effects.

\section{Materials and methods}

Reagents and antibodies. A mutant form of Gal-9 lacking the entire linker region was recombinantly produced and 
purified as described in our previous report (24). Fetal bovine serum (FBS) was purchased from Wako Pure Chemical Industries, Ltd., (Osaka, Japan), Cell Counting kit-8 (CCK-8) was purchased from Dojindo Laboratories (Kumamoto, Japan), and all other chemicals were obtained from Sigma Chemical Corp. (Tokyo, Japan). Z-VAD-FMK and Z-DEVD-FMK were purchased from AdooQ Bioscience (Irvine, CA, USA).

The primary antibodies used in the present study included monoclonal anti- $\beta$-actin (A5441, 1:3,000; Sigma-Aldrich, St. Louis, MO, USA), anti-cyclin D1 (RB-9041, 1:1,000; Thermo Fisher Scientific, Waltham, MA, USA), anti-cyclin E (1:1,000; Thermo Fisher Scientific), anti-Cdk6 (sc-177, 1:1,000; Santa Cruz Biotechnology, Santa Cruz, CA, USA), anti-Cdk4 (sc-749, 1:1,000; Santa Cruz Biotechnology), anti-Cdk2 (sc-163, 1:2,000; Santa Cruz Biotechnology) and anti-phosphorylated retinoblastoma protein $(558385,1: 1,000$ Rb; BD Biosciences, San Jose, CA, USA). Antibodies to caspase-3 (\#9665), cleaved caspase-3 (\#9664), caspase-7 (\#12827), caspase-9 (\#9508), cleaved caspase-9 (\#7237), PARP (\#9542), cleaved PARP (\#5625), LC3 (\#12741) and SQSTM1/ p62 (\#8025) were purchased from Cell Signaling Technology (Boston, MA, USA).

The secondary antibodies used in the present study included horseradish peroxidase (HRP)-conjugated antimouse and anti-rabbit IgG antibodies purchased from Cell Signaling Technology (1:2,000 each).

Cell culture and cell proliferation assay. Four human EAC cell lines (OE19, OE33, SK-GT4 and OACM5.1c) were obtained from the European Collection of Authenticated Cell Cultures (ECACC). All cell lines were grown in RPMI-1640 medium (Gibco/Invitrogen, Carlsbad, CA, USA) supplemented with $10 \% \mathrm{FBS}$ and $9100 \mathrm{mg} / \mathrm{l}$ of penicillin-streptomycin (Invitrogen) at $37^{\circ} \mathrm{C}$ in a humidified atmosphere containing $5 \% \mathrm{CO}_{2}$.

Cell proliferation was assayed using a Cell Counting kit- 8 (CCK-8) according to the manufacturer's instructions. Briefly, $5 \times 10^{3}$ cells were seeded into each well of a 96-well plate and cultured in $100 \mu \mathrm{l}$ of RPMI-1640 medium supplemented with $10 \%$ FBS. After $24 \mathrm{~h}$, Gal-9 $(0,0.1,0.3$ or $1.0 \mu \mathrm{M})$ was added to each well, and the cells were cultured for an additional $48 \mathrm{~h}$. Then, the CCK-8 reagent $(10 \mu \mathrm{l})$ was added to each well, and the plates were incubated at $37^{\circ} \mathrm{C}$ for $3 \mathrm{~h}$. The absorbance of each well was measured at $450 \mathrm{~nm}$ using a microplate reader.

ELISA to assess apoptosis. Caspase-cleaved cytokeratin 18 (CCK18) expression was evaluated using an M30 Apoptosense ELISA kit obtained from Peviva AB (Bromma, Sweden) according to the manufacturer's instructions (25). Cells $\left(5 \times 10^{3} /\right.$ well) were seeded into 96 -well plates, cultured in $100 \mu 1$ of culture medium for $24 \mathrm{~h}$ and then treated with $0.3 \mu \mathrm{M}$ Gal-9. The antigen concentrations in the control and treated samples were calculated via interpolation from a standard curve.

Cell cycle and apoptosis analyses. The cell cycle and apoptosis analyses were performed separately using a Cell Cycle Phase Determination kit (Cayman Chemical, Ann Arbor, MI, USA) and an Annexin V-FITC Early apoptosis detection kit (Cell Signaling Technology), respectively.
SK-GT4 cells $\left(1.0 \times 10^{6}\right.$ cells in a $100-\mathrm{mm}$ dish $)$ were treated with $0.3 \mu \mathrm{M}$ Gal-9 for $48 \mathrm{~h}$, and untreated cells were used as the controls. The cell cycle profiles were analyzed by measuring the propidium iodide (PI)-labeled DNA content in ethanol-fixed cells. Fixed cells were washed with phosphatebuffered saline (PBS) and then stored at $-20^{\circ} \mathrm{C}$ prior to flow cytometric analysis. On the day of the analysis, the cells were washed with cold PBS, suspended in $100 \mu \mathrm{l}$ of PBS with $10 \mu \mathrm{l}$ of RNase A $(250 \mu \mathrm{g} / \mathrm{ml})$ and incubated for $30 \mathrm{~min}$. Then, $110 \mu \mathrm{l}$ of PI stain $(100 \mu \mathrm{g} / \mathrm{ml})$ was added to each cell suspension, and the cells were incubated at $4^{\circ} \mathrm{C}$ for at least $30 \mathrm{~min}$ prior to the analysis. Apoptotic and necrotic cell death were analyzed by performing double staining with FITC-conjugated Annexin V and PI; this staining method is based on the binding of Annexin V to apoptotic cells with exposed phosphatidylserine residues and the binding of PI to late apoptotic/necrotic cells with membrane damage. Tumor cells were treated with $0.3 \mu \mathrm{M}$ Gal-9 for either 12 or $24 \mathrm{~h}$ and untreated cells were used as the controls. Staining was performed according to the manufacturer's instructions. Flow cytometry was performed using a Cytomics FC 500 flow cytometer (Beckman Coulter, Indianapolis, IN, USA), and the proportions of stained cells were analyzed using the Kaluza software (Beckman Coulter). All experiments were performed in triplicate.

Gel electrophoresis and western blotting. SK-GT4 cells were seeded at a density of $1.0 \times 10^{6}$ cells $/ 100-\mathrm{mm}$ dish and cultured for $24 \mathrm{~h}$. Then, $0.3 \mu \mathrm{M}$ Gal-9 was added, and the cells were cultured for an additional 24-48 h. Next, the cells were lysed in a protease inhibitor cocktail (Complete protease inhibitor mixture; iNtRON Biotechnology, Sungnam, Korea) on ice for $20 \mathrm{~min}$. Suspensions of lysed cells were centrifuged at $13,000 \mathrm{x} \mathrm{g}$ at $4^{\circ} \mathrm{C}$ for $5 \mathrm{~min}$, and supernatants containing soluble cellular proteins were harvested and stored at $-80^{\circ} \mathrm{C}$ until use. The protein concentrations were measured using a NanoDrop 2000 fluorospectrometer (Thermo Fisher Scientific). Protein aliquots (1-10 $\mu \mathrm{g}$ ) were resuspended in sample buffer, separated on $10 \%$ Tris-glycine gradient gels by SDS-PAGE (26), and then transferred to nitrocellulose membranes. After blocking, the membranes were incubated with primary antibodies, followed by incubation with HRP-conjugated secondary antibodies (27). Immunoreactive proteins were visualized with an enhanced chemiluminescence detection system (Perkin-Elmer Co., Waltham, MA, USA) on X-ray film.

Angiogenic profile analysis. SK-GT4 cells were seeded $\left(6.0 \times 10^{6}\right.$ cells $/ 100 \mathrm{~mm}$-diameter dish) and treated with $0.3 \mu \mathrm{M}$ Gal-9, while control cells remained untreated; all cells were cultured with RPMI-1640 medium supplemented with 10\% FBS for $24 \mathrm{~h}$ and then lysed in PRO-PREP. A RayBio Human Angiogenesis Antibody array (RayBiotech, Inc., Norcross, GA, USA) was employed according to the manufacturer's protocol. This protocol includes a spot-based assay that facilitates the detection and comparison of 20 angiogenic cytokines. Each array membrane was exposed to X-ray film, and the signals were detected using a chemiluminescence detection system (Perkin-Elmer). The immunoreactive band densities obtained with this array were analyzed by densitometric scanning (TIc scanner; Shimizu, Co., Ltd., Kyoto, Japan). 

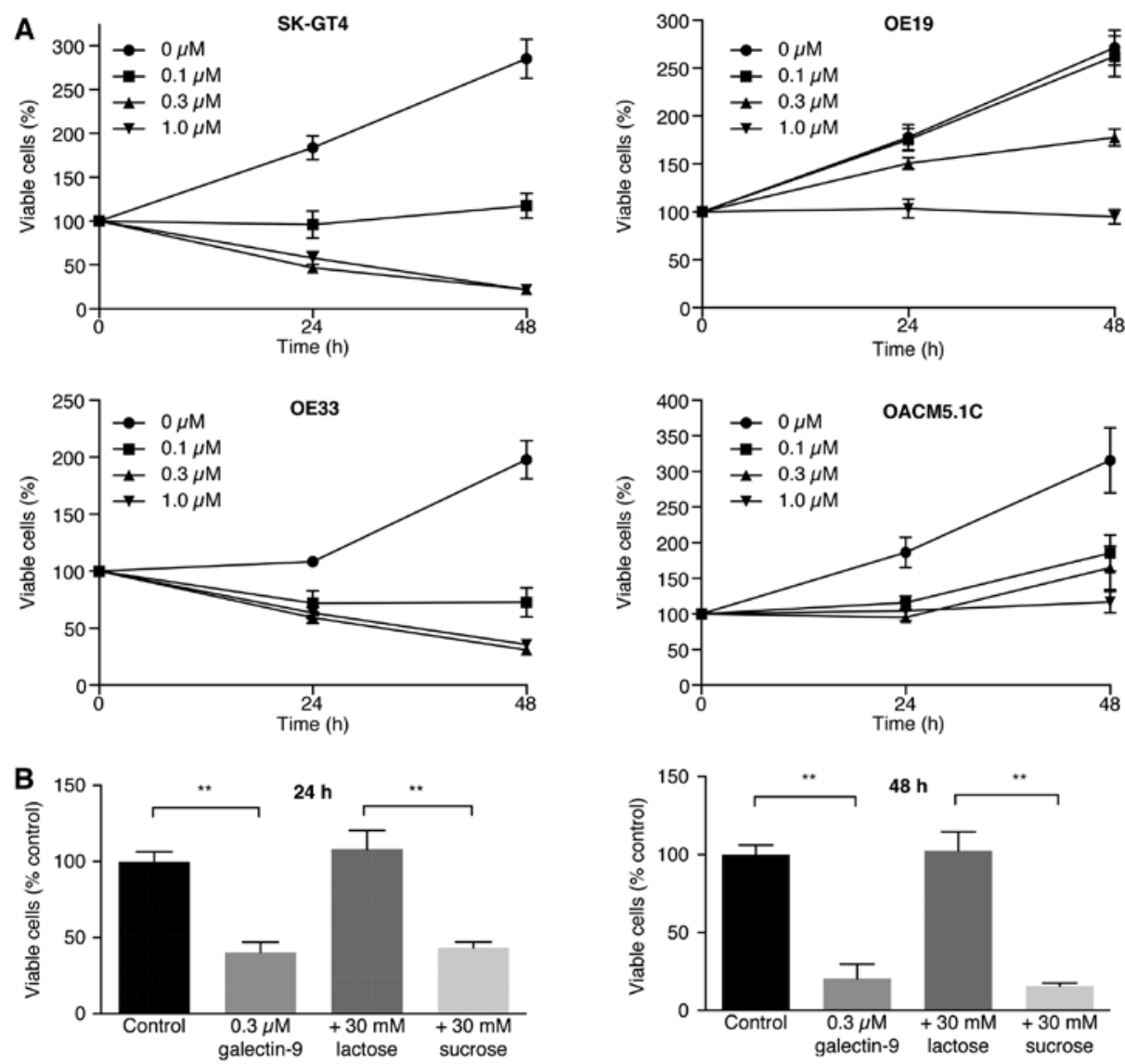

Figure 1. Gal-9 suppresses the proliferation of esophageal adenocarcinoma cells. (A) OE19, OE33, SK-GT4 and OACM 5.1C cells were seeded into 96-well plates. After $24 \mathrm{~h}, \mathrm{Gal}-9(0,0.1,0.3$, or $1.0 \mu \mathrm{mol} / \mathrm{l})$ or vehicle was added to the culture medium; the cells were enumerated $24 \mathrm{~h}$ later by performing a CCK assay. OE19, OE33, SK-GT4 and OACM 5.1C cells (5,000/well) were seeded into 96-well plates, and Gal-9 was added as described above. Cell viability was assayed daily from 0 to $48 \mathrm{~h}$. The viability of the Gal-9-treated cells differed significantly from the viability of the control cells $(\mathrm{P}<0.05)$. (B) The antagonistic effect of lactose against galectin-9 (Gal-9). SK-GT4 cells were incubated with or without $30 \mathrm{mM}$ lactose in addition to $0.3 \mu \mathrm{M}$ Gal-9 for $48 \mathrm{~h}$. The effect of Gal-9 was antagonized by lactose, suggesting that the $\beta$-galactosidase-binding nature of Gal-9 was essential for its activity ( $\left.{ }^{* *} \mathrm{P}<0.01\right)$.

Phosphorylated receptor tyrosine kinase ( $p$-RTK) antibody arrays. SK-GT4 cells were treated with $0.3 \mu \mathrm{M}$ Gal-9 for $24 \mathrm{~h}$ and then lysed in PRO-PREP. Human phospho-RTKs were assayed using a Human Phospho-RTK Array kit (R\&D Systems, Minneapolis, MN, USA) according to the manufacturer's instructions. Each array membrane was exposed to $\mathrm{X}$-ray film, and the signals were detected using a chemiluminescence detection system (Perkin-Elmer).

Analysis of miRNA arrays. SK-GT4 cells were treated with $0.3 \mu \mathrm{M}$ Gal-9 for $24 \mathrm{~h}$ and then stored in the RNAprotect reagent (Qiagen, Venlo, The Netherlands). Total RNA was extracted from each cell line using a miRNeasy Mini kit (Qiagen) according to the manufacturer's instructions, and the RNA quantity and quality were measured using an RNA 6000 Nano kit (Agilent Technologies, Santa Clara, CA, USA). The samples were labeled using a miRCURY Hy3 Power Labeling kit (Exiqon A/S, Vedbaek, Denmark) and hybridized to a human miRNA oligo chip (v.21; Toray Industries, Tokyo, Japan). Scanning was performed using a 3D-Gene Scanner 3000 (Toray Industries). The 3D-Gene extraction version 1.2 software (Toray Industries) was used to read the raw intensities from the images. To detect differences in miRNA expression between the Gal-9-treated and control samples, the raw data were analyzed using the GeneSpring
GX 10.0 software (Agilent Technologies). Quantile normalization was performed for raw data above background levels, and differentially expressed miRNAs were identified using the Mann-Whitney U test. Hierarchical clustering was performed using the farthest neighbor method with the absolute uncentered Pearson's correlation coefficient as a metric. A heat map was produced with the base-2 logarithms of the intensities median-centered for each row to depict the relative expression intensity of each miRNA.

Statistical analysis. All statistical analyses were performed using the GraphPad Prism 6 software (GraphPad Software, Inc., La Jolla, CA, USA). Comparisons between the treated and control groups were performed using two-tailed paired or unpaired Student's t-tests. A P $<0.05$ was considered significant.

\section{Results}

Gal-9 suppresses human esophageal adenocarcinoma cell proliferation. The effects of Gal-9 on the proliferation of four EAC cell lines (OE19, OE33, SK-GT4 and OACM5.1c) were evaluated. The cells were grown in 10\% FBS and treated with $0,0.1,0.3$ or $1.0 \mu \mathrm{mol} / 1 \mathrm{Gal}-9$ for $48 \mathrm{~h}$. Gal-9 inhibited the proliferation of all four EAC cell lines in a dose-dependent manner (Fig. 1). 
A
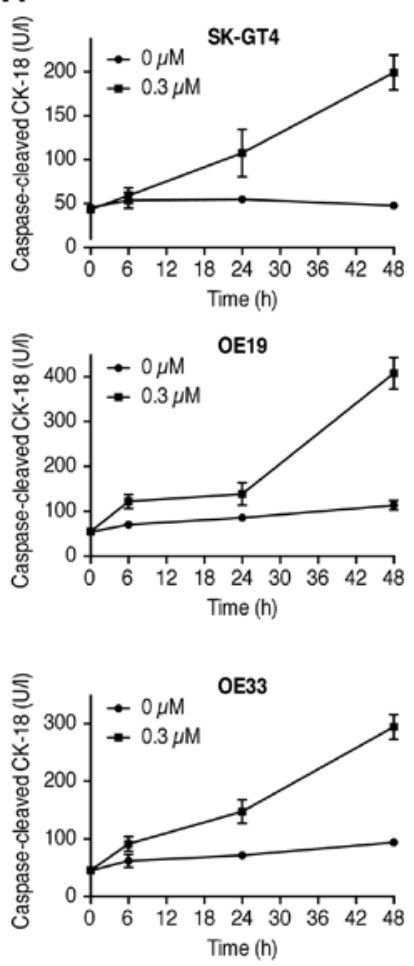

D

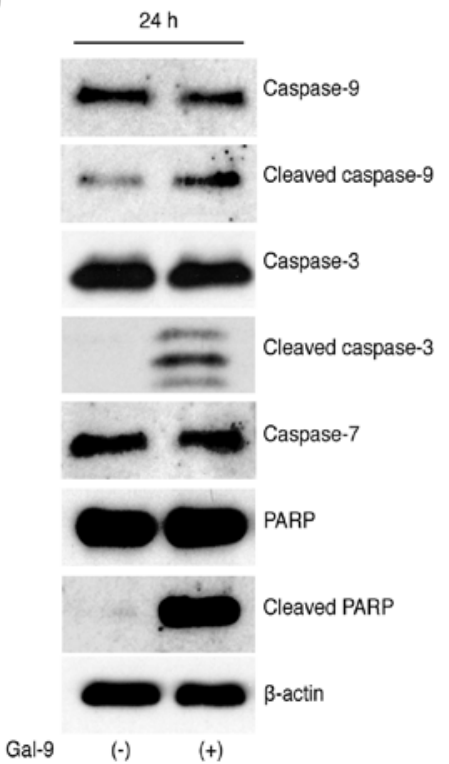

B
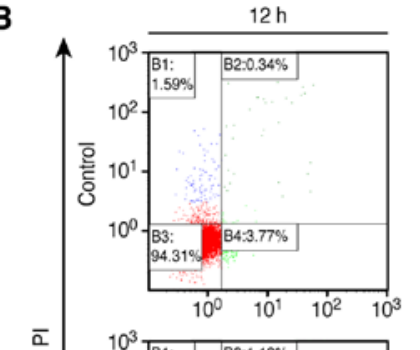

$\overline{\mathbf{a}}$

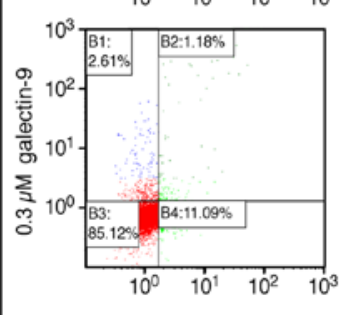

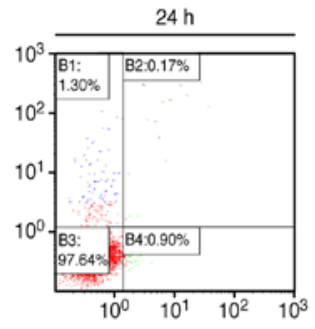

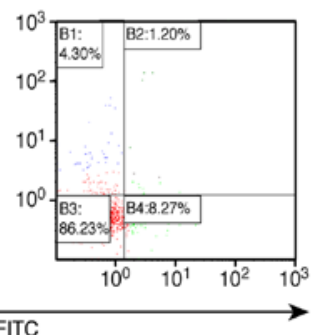

C

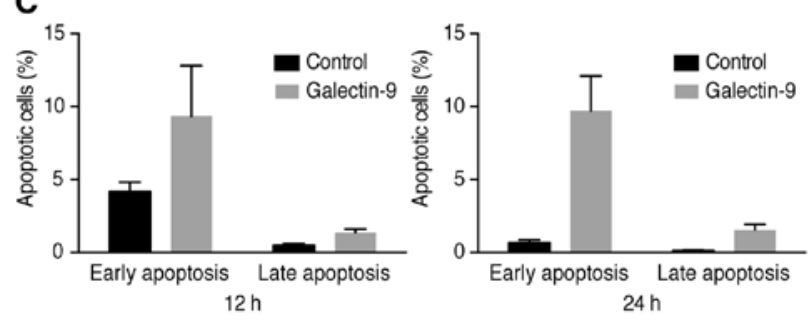

E

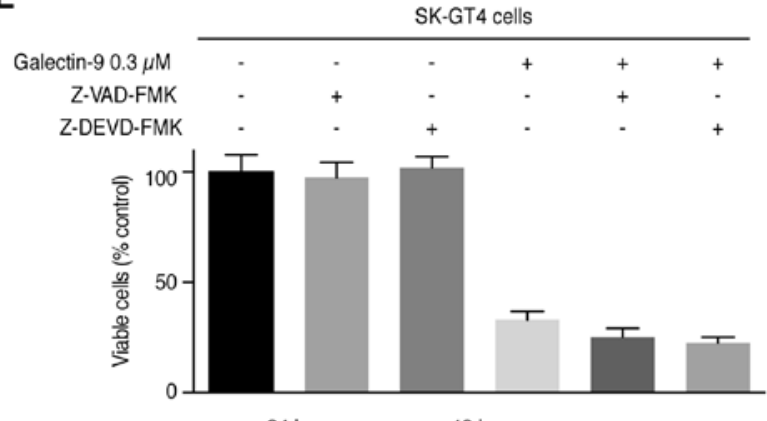

F

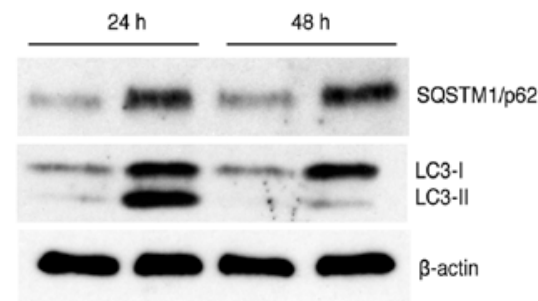

Gal-9

$(-)$

$(+)$

(-)

$(+)$

Figure 2. Investigation of the mechanism underlying the apoptotic effects of Gal-9. (A) Cells were incubated in the presence or absence of 0.3 M Gal-9. Gal-9 increased the caspase-cleaved keratin 18 levels in the SK-GT4, OE19 and OE33 cells, suggesting the involvement of intermediate filament cleavage in the apoptotic process following phosphatidylserine exposure. The CCK18 levels in the Gal-9-treated EAC cells differed significantly from the levels in the control cells $(\mathrm{P}<0.05)$. (B and C) The analysis of apoptosis in Gal-9-treated SK-GT4 cells revealed the induction of apoptosis by Gal-9. (D) Western blotting revealed increased activated caspase-3 and caspase-9 expression levels in SK-GT4 cells following Gal-9 treatment, but no effects on the total caspase-3 and caspase-9 levels. (E) Caspase-independent cell death induction by Gal-9 in SK-GT4 cells. SK-GT4 cell were treated with $0.3 \mu \mathrm{M}$ Gal-9 for $24 \mathrm{~h}$ with or without pretreatment with either $50 \mu \mathrm{M}$ Z-VAD-FMK or Z-DEVD-FMK for $1 \mathrm{~h}$. (F) Gal-9 inhibited the autophagy flux in SK-GT4 cells. SK-GT4 cells were treated with 0 or $0.3 \mu \mathrm{M}$ Gal-9 for $48 \mathrm{~h}$, and the autophagy markers LC3 and SQSTM1/p62 were detected by western blot analysis.

Gal-9 exhibits antitumor effects in EAC cells by inducing apoptosis. To determine whether Gal-9 induces apoptosis, SK-GT4, OE19 and OE33 cells were treated with $0.3 \mu \mathrm{M}$ Gal-9, and the CCK18 levels were measured following treatment using an M30 ELISA kit. The results of Annexin V-FITC/PI staining and the flow cytometric analysis demonstrated that Gal-9 significantly increased the CCK-18 levels in the three EAC cell lines (Fig. 2A) and also induced apoptosis of the SK-GT4 cells in a dose- and time-dependent manner. The different quadrants presented in Fig. 2B represent living cells (lower left quadrant), early apoptotic cells (lower right quadrant), and late apoptotic cells (upper right quadrant). The increased numbers of earlyand late-phase apoptotic cells indicated that the antitumor effects of Gal-9 involved induction of apoptosis (Fig. 2C). This apoptotic induction was accompanied by increases in 
A

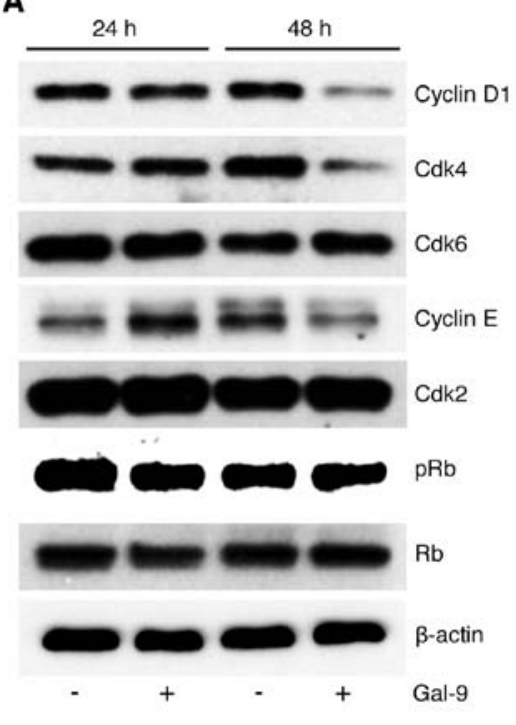

B

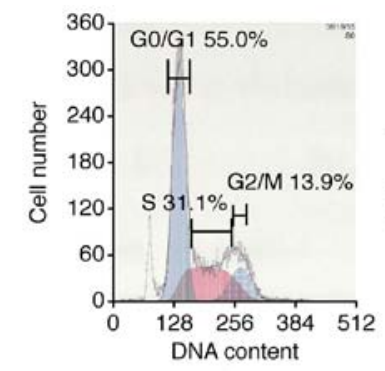

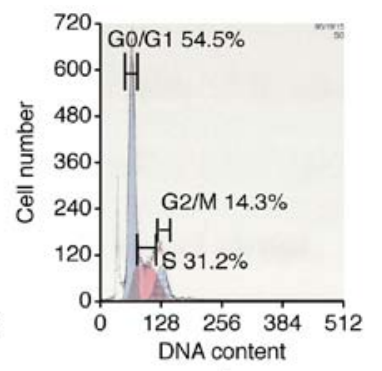
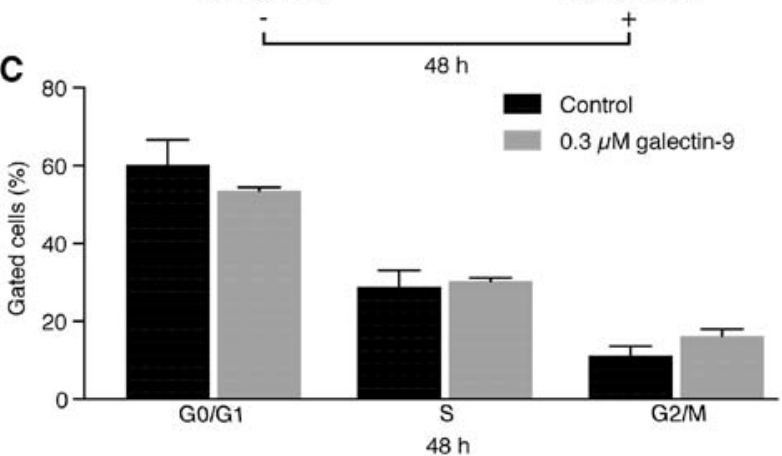

Figure 3. Western blotting and flow cytometric analysis of SK-GT4 cell cycle profiles. (A) Expression of cyclin D1, cyclin E, Cdk2, Cdk4, Cdk6, phosphorylated $\mathrm{Rb}(\mathrm{pRb})$ and $\mathrm{Rb}$ in SK-GT4 cells 24 and $48 \mathrm{~h}$ after the addition of $0.3 \mu \mathrm{M}$ Gal-9. Protein expression was assayed by western blotting. (B) Flow cytometric analysis of proliferating SK-GT4 cells $48 \mathrm{~h}$ after the addition of $0.3 \mu \mathrm{M}$ Gal-9. (C) The cell cycle profiles of the SK-GT4 cells did not change after Gal-9 treatment.

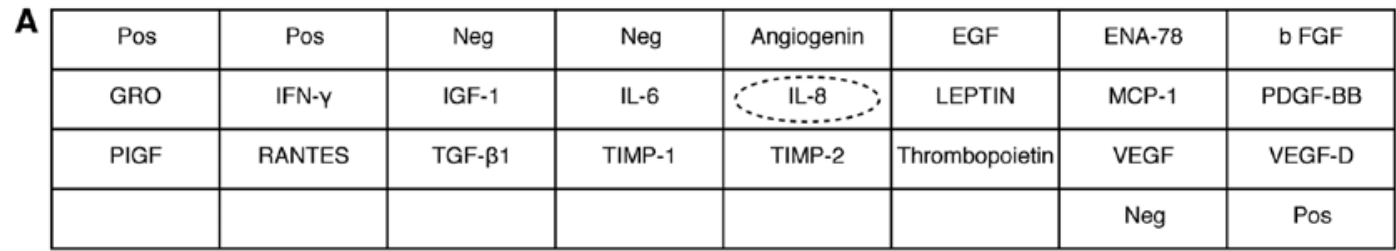

B

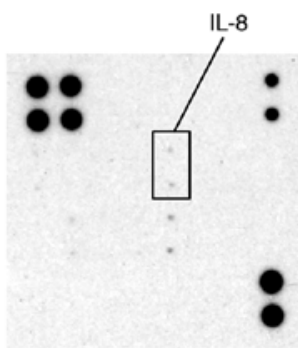

Gal-9 (-)

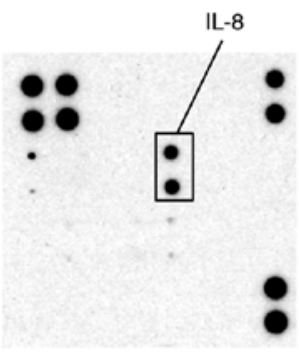

Gal-9 (+)
C

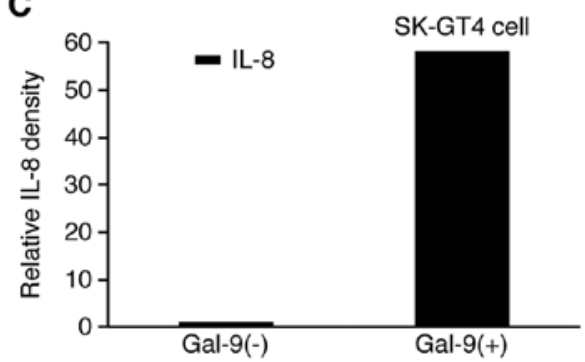

Figure 4. Effects of Gal-9 on SK-GT4 cell angiogenesis. (A) Template showing the locations of angiogenesis-related proteins spotted onto a human angiogenesis array. (B) Representative expression levels of various angiogenesis-related proteins in SK-GT4 cells cultured with or without Gal-9. (C) The densitometric ratio of IL-8 spots for Gal-9-treated vs. untreated cells was 58.2-fold.

the cleaved caspase-3, cleaved caspase-9 and cleaved PARP levels (Fig. 2D). The blockade of caspase activation by treatment with either the pan-caspase inhibitor Z-VAD-FMK or caspase-3 inhibitor Z-DEVD-FMK did not protect the cells from Gal-9-induced cell death (Fig. 2E). Thus, Gal-9 may suppress the proliferation of EAC cells by inducing apoptosis via a caspase-independent pathway. Because apoptosis often occurs simultaneously with autophagy, this process is also involved in the antitumor effect of Gal-9. Therefore, we evaluated the levels of SQSTM1/p62 and LC3-II, which are key proteins involved in autophagy regulation, after treatment with Gal-9 for $24 \mathrm{~h}$. As shown in Fig. 2F, the accumulation of LC3-II and upregulation of SQSTM1/p62 were observed in the treated SK-GT4 cells, indicating that Gal-9 may inhibit the autophagic flux.

No specific effects of Gal-9 are observed on cell cycle regulatory proteins in SK-GT4 cells. The effects of Gal-9 on the expression of various cell cycle-related molecules in SK-GT4 cells were evaluated by western blotting. SK-GT4 cells were treated with $0.3 \mu \mathrm{M}$ Gal-9 for $48 \mathrm{~h}$. Gal-9 treatment resulted in progressive decreases in the cyclin D1, cyclin E and Cdk4 levels but had no effects on the levels of other cell cycle regulatory proteins (Fig. 3A). 


\begin{tabular}{|c|c|c|c|c|c|c|c|c|c|c|c|}
\hline A \\
$\begin{array}{c}\text { Reference } \\
\text { spots }\end{array}$ & & & & & & & & & & & $\begin{array}{c}\text { Reference } \\
\text { spots }\end{array}$ \\
\hline EGFR & ErbB2 & ErbB3 & ErbB4 & FGFR1 & FGFR2a & FGFR3 & FGFR4 & InsulinR & IGF-1R & Axl & Dtk \\
\hline Mer & HGFR & MSPR & PDGFRa & PDGF R & SCFR & FIt-3 & M-CSFR & C-Ret & ROR1 & ROR2 & Tie-1 \\
\hline Tie-2 & TrkA & TrkB & TrkC & VEGF R1 & VEGF R2 & VEGF R3 & MuSK & EphA1 & EphA2 & EphA3 & EphA4 \\
\hline EphA6 & EphA7 & EphB1 & EphB2 & EphB4 & EphB6 & ALK & DDR1 & DDR2 & EphA5 & EphA10 & \\
\hline $\begin{array}{c}\text { Reference } \\
\text { spots }\end{array}$ & & EphB3 & PYK & & & & & & & & PBS \\
\hline
\end{tabular}

B

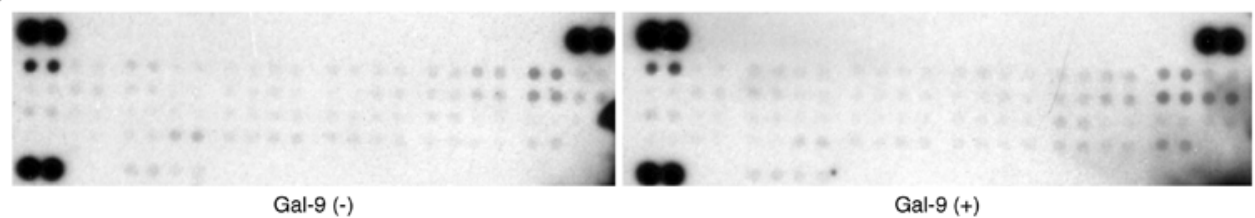

Figure 5. Effects of Gal-9 on pRTKs in SK-GT4 cells. (A) Template showing the locations of tyrosine kinase antibodies spotted onto a human phospho-RTK array. (B) Representative expression of various phosphorylated receptor tyrosine kinases in SK-GT4 cells cultured with or without Gal-9. The pRTK levels did not change following Gal-9 treatment.

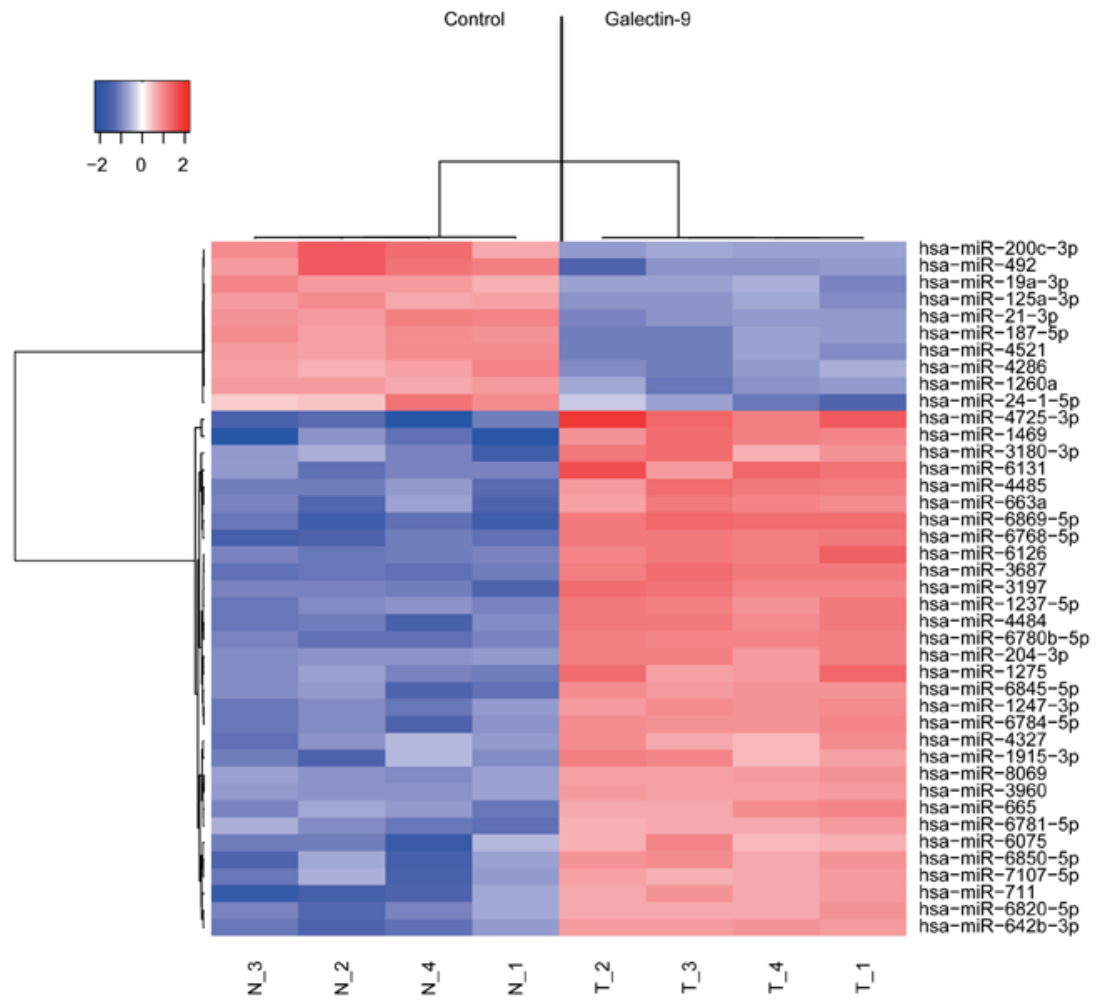

Figure 6. Hierarchical clustering of SK-GT4 cells cultured with or without Gal-9 according to the expression profiles of numerous differentially expressed miRNAs. The analyzed samples are shown in the columns, and the miRNAs are presented in the rows. The miRNA clustering color scale presented at the top indicates the relative miRNA expression levels, with red and blue representing high and low expression levels, respectively.

To elucidate the mechanism of action of Gal-9 in the control of SK-GT4 cell proliferation, cell cycle progression was examined by flow cytometry. No changes were observed in the cell cycle profiles of SK-GT4 cells treated with $0.3 \mu \mathrm{M}$ Gal-9 (Fig. 3B), suggesting that Gal-9 suppressed EAC cell growth through tumor cell apoptosis but not through cell cycle arrest.

Gal-9 treatment affects the expression of angiogenesis-related molecules. We used an angiogenesis array system (Fig. 4A) to identify the key angiogenesis-related molecules associated with the antitumor effects of Gal-9 in SK-GT4 cells. Of the 20 angiogenesis molecules screened, only the interleukin (IL)-8 levels increased in vitro following Gal-9 treatment (Fig. 4B). The densitometric ratio of IL-8 spots for Gal-9-treated vs. untreated cells was 58.2-fold (Fig. 4C).

Effects of Gal-9 on p-RTKs in SK-GT4 cells. A p-RTK array system was used to identify the key RTKs associated with the antitumor effects of Gal-9. The use of an antibody 
Table I. Relative expression levels and chromosomal locations of miRNAs in SK-GT4 cells cultured with or without Gal-9.

\begin{tabular}{|c|c|c|c|}
\hline miRNA & $\begin{array}{c}\text { Fold change } \\
\text { (Treated/ } \\
\text { untreated) }\end{array}$ & P-value & $\begin{array}{c}\text { Chromosomal } \\
\text { location }\end{array}$ \\
\hline \multicolumn{4}{|l|}{ Upregulated } \\
\hline hsa-miR-4725-3p & 7.72 & 0.0286 & 17 \\
\hline hsa-miR-6869-5p & 6.38 & 0.0294 & 20 \\
\hline hsa-miR-1469 & 5.95 & 0.0286 & $15 q 26.2$ \\
\hline hsa-miR-6768-5p & 5.44 & 0.0294 & 16 \\
\hline hsa-miR-3687 & 5.13 & 0.0286 & 21 \\
\hline hsa-miR-6131 & 4.92 & 0.0286 & 5 \\
\hline hsa-miR-3197 & 4.76 & 0.0294 & 21 \\
\hline hsa-miR-4484 & 4.75 & 0.0286 & 10 \\
\hline hsa-miR-6126 & 4.69 & 0.0286 & 16 \\
\hline hsa-miR-4485 & 4.50 & 0.0286 & 11 \\
\hline hsa-miR-6780b-5p & 4.42 & 0.0294 & 6 \\
\hline hsa-miR-663a & 4.25 & 0.0286 & 20p11.1 \\
\hline hsa-miR-711 & 4.23 & 0.0286 & 3 \\
\hline hsa-miR-1237-5p & 4.23 & 0.0286 & 11 \\
\hline hsa-miR-1275 & 4.05 & 0.0286 & 6 \\
\hline hsa-miR-3180-3p & 3.96 & 0.0286 & 16 \\
\hline hsa-miR-6784-5p & 3.94 & 0.0286 & 17 \\
\hline hsa-miR-6845-5p & 3.91 & 0.0286 & 8 \\
\hline hsa-miR-642b-3p & 3.77 & 0.0294 & 19 \\
\hline hsa-miR-1247-3p & 3.70 & 0.0286 & $14 q 32.31$ \\
\hline hsa-miR-6850-5p & 3.69 & 0.0286 & 8 \\
\hline hsa-miR-204-3p & 3.61 & 0.0294 & $9 q 21.12$ \\
\hline hsa-miR-1915-3p & 3.50 & 0.0286 & $10 \mathrm{p} 12.31$ \\
\hline hsa-miR-6075 & 3.37 & 0.0286 & 5 \\
\hline hsa-miR-665 & 3.29 & 0.0286 & $14 q 32.2$ \\
\hline hsa-miR-6820-5p & 3.27 & 0.0286 & 22 \\
\hline hsa-miR-7107-5p & 3.22 & 0.0286 & 12 \\
\hline hsa-miR-6781-5p & 3.14 & 0.0286 & 17 \\
\hline hsa-miR-4327 & 3.04 & 0.0286 & 21 \\
\hline hsa-miR-8069 & 3.04 & 0.0294 & 21 \\
\hline hsa-miR-3960 & 3.02 & 0.0275 & 9 \\
\hline \multicolumn{4}{|l|}{ Downregulated } \\
\hline hsa-miR-492 & 0.23 & 0.0286 & $12 q 22$ \\
\hline hsa-miR-200c-3p & 0.27 & 0.0286 & $12 \mathrm{p} 13.31$ \\
\hline hsa-miR-21-3p & 0.28 & 0.0286 & $17 q 23.1$ \\
\hline hsa-miR-4521 & 0.29 & 0.0286 & 17 \\
\hline hsa-miR-187-5p & 0.29 & 0.0294 & $18 \mathrm{q} 12.2$ \\
\hline hsa-miR-1260a & 0.32 & 0.0294 & 14 \\
\hline hsa-miR-24-1-5p & 0.32 & 0.0286 & $9 q 22.32$ \\
\hline hsa-miR-4286 & 0.32 & 0.0294 & 8 \\
\hline hsa-miR-125a-3p & 0.32 & 0.0286 & $19 q 13.41$ \\
\hline hsa-miR-19a-3p & 0.33 & 0.0286 & $13 q 31.3$ \\
\hline
\end{tabular}

Fold-change $(\mathrm{FC})>3.0, \mathrm{FC}<0.33, \mathrm{P}<0.05$. array (Fig. 5A) enabled the evaluation of the expression of 49 activated RTKs in SK-GT4 cells and tumors in the presence and absence of Gal-9. The activated RTK levels did not change following Gal-9 treatment (Fig. 5B).

Effects of Gal-9 on miRNA expression. Using a custom microarray platform, we analyzed the expression of 2,555 miRNA probes in cell lines cultured in the presence and absence of Gal-9. Treatment of SK-GT4 cells with $0.3 \mu \mathrm{mol} / 1 \mathrm{Gal}-9$ for $48 \mathrm{~h}$ resulted in the significant upregulation of 31 miRNAs and in the significant downregulation of 10 miRNAs (Table I).

An unsupervised hierarchical clustering analysis performed by calculating Pearson's correlation coefficient revealed clustering of the cell lines treated with Gal-9 in vitro; the miRNA expression patterns of the treated cells were distinct from the patterns of the untreated cell lines (Fig. 6).

\section{Discussion}

Based on the results of the present study, Gal-9 suppresses the cell proliferation and tumor growth of human EAC cell lines in vitro. The antitumor effects of Gal-9 on T cell homeostasis, cell aggregation and metastasis are well known $(13,14)$. Additionally, Gal-9 inhibits the proliferation of hematologic malignancies, such as multiple myeloma (17) and chronic myeloid leukemia (18) and significantly retards the growth of myeloma xenografts in mice (17). Furthermore, cell surfaceassociated Gal-9 triggers the aggregation of melanoma cells, which is indicative of the Gal-9-mediated activation of cellular adhesion and inhibition of cell detachment (19,20). Although Gal-9 may suppress the proliferation and tumor growth of hematologic malignancies in vitro and in vivo, Gal-9 exerts different effects on solid malignancies. For example, breast cancer cell lines with high endogenous Gal-9 levels exhibit a strong tendency to aggregate, whereas cells with low Gal-9 levels do not (28). Importantly, ectopic expression of endogenous Gal-9 and treatment with recombinant Gal-9 trigger the formation of tight cellular clusters $(19,28)$. Therefore, Gal-9 directly suppresses cell proliferation and tumor growth and has therapeutic potential for several solid tumors.

Recombinant Gal-9 induces apoptosis and cell death through apoptotic signaling pathways $(17,18)$. In multiple myeloma cells, apoptotic signaling is induced via the activation of the MAP kinases JNK and p38 (17). Additionally, Gal-9 induces the pro-apoptotic Bcl-2 family member Noxa via activation of transcription factor 3 , leading to the death of chronic myeloma cells (18). Moreover, various hematologic malignancies are sensitive to apoptotic elimination by recombinant Gal-9. Cleavage of cytokeratin 18 occurs as an early event during apoptosis following the activation of apoptosis executioners, particularly effector caspases, but remains intact during other types of cell death, such as autophagy and necrosis (29).

Gal-9 induces apoptosis through both caspase-dependent and caspase-independent mechanisms $(17,20)$. In previous studies, Gal-9 increased the levels of cleaved cytokeratin-18 in various cancer cell lines in a dose- and time-dependent manner (21-23,31). Based on our data, Gal-9 also increased CCK18 levels in the three EAC cell lines. Additionally, Gal-9 increased the activated caspase-3, caspase-9 and PARP 
levels. The death receptor and mitochondrial pathways are the two major pathways that initiate apoptotic responses, and caspase- 3 is the key executioner caspase in both pathways (32). The present study revealed that the apoptosis of EAC cells was initiated through caspase-independent pathways. Recently, Wiersma et al (30) showed an association of Gal-9 with impaired lysosomal function and fatal frustrated autophagy. Gal-9 converts LC3-I to LC3-II, whereas SQSTM1/p62 is increased after Gal-9 treatment for 24-48 h. Moreover, the inhibition of autophagosomelysosome fusion and LC3-II-SQSTM1/p62 accumulation by the lysosomal inhibitor chloroquine has previously been reported. Combination therapies using autophagy inhibitors and standard chemotherapies have been proposed for many cancer types, and these findings indicate that Gal-9 may have a synergic effect in such a combination therapy for acquired therapeutic resistance.

The expression levels of cell cycle-related proteins were unchanged or only slightly altered $48 \mathrm{~h}$ after the addition of Gal-9. Additionally, the results of the flow cytometric analysis revealed no effects of Gal-9 on the G0 to G1 transition in EAC cells in vitro. Thus, the antitumor effects of Gal-9 may not be related to a reduction in the levels of various cell cycle-related proteins.

IL-8 in tumors and the tumor microenvironment contributes to tumor progression by regulating angiogenesis and cancer cell growth and survival (33). In patients with esophageal cancer, the elevated expression of IL- 8 and its receptor CXCR-2 has been associated with a poor prognosis (34). Based on our data, Gal-9 increased IL-8 expression in Gal-9-treated SK-GT4 cells. Acquired Gal-9 resistance in EAC cells may be attributable to Gal-9-induced IL-8 expression; thus, the applicability of Gal-9 for EAC treatment may be limited to the tumor microenvironment and angiogenesis. Conversely, the levels of 49 pRTKs did not change following treatment of the human EAC cell lines with Gal-9.

The miRNAs associated with the antitumor effects of Gal-9 were assessed using miRNA expression arrays. The cluster analysis clearly showed the effects of Gal-9 treatment on the miRNA expression levels in cancer cells. We identified 41 miRNAs that were differentially expressed in the Gal-9treated EAC cells. These miRNAs are important candidates to gauge the effectiveness of Gal-9 treatment and provide insights into the molecular basis of Gal-9-mediated antitumor effects, particularly those mediated by miRNAs.

miR-200c expression was upregulated in hepatocellular carcinoma (35) and ovarian cancer (36) tissues compared with their respective normal tissues. Additionally, the overexpression of miR-200c in esophageal cancer was associated with unfavorable responses to chemotherapy and poor prognoses (37) because this miRNA supported tumor growth by directly suppressing PPP2R1 and promoting Akt activation (38). The present study was not able to determine whether miR-200c acted as an oncogenic or tumor-suppressive molecule. However, Gal-9 treatment downregulated miR-200c expression in EAC cells, which may be associated with the antitumor effects of Gal-9.

In conclusion, Gal-9 suppresses human EAC cell proliferation, possibly by inducing apoptosis in a miRNA-dependent manner.

\section{Acknowledgements}

We thank Ms. Noriko Murao and Ms. Kana Ogawa for providing technical assistance.

\section{References}

1. Gaur P, Hunt CR and Pandita TK: Emerging therapeutic targets in esophageal adenocarcinoma. Oncotarget 7: 48644-48655, 2016.

2. Edgren G, Adami HO, Weiderpass E and Nyrén O: A global assessment of the oesophageal adenocarcinoma epidemic. Gut 62: 1406-1414, 2013.

3. Rubenstein JH and Shaheen NJ: Epidemiology, diagnosis, and management of esophageal adenocarcinoma. Gastroenterology 149: 302-17.e1, 2015

4. Pennathur A, Farkas A, Krasinskas AM, Ferson PF, Gooding WE, Gibson MK, Schuchert MJ, Landreneau RJ and Luketich JD: Esophagectomy for T1 esophageal cancer: Outcomes in 100 patients and implications for endoscopic therapy. Ann Thorac Surg 87: 1048-1054, discussion 1054-1055, 2009.

5. Enzinger PC and Mayer RJ: Esophageal cancer. N Engl J Med 349: 2241-2252, 2003.

6. Matsumoto R, Matsumoto H, Seki M, Hata M, Asano Y, Kanegasaki S, Stevens RL and Hirashima M: Human ecalectin, a variant of human galectin-9, is a novel eosinophil chemoattractant produced by T lymphocytes. J Biol Chem 273: 16976-16984, 1998.

7. Matsushita N, Nishi N, Seki M, Matsumoto R, Kuwabara I, Liu FT, Hata Y, Nakamura T and Hirashima M: Requirement of divalent galactoside-binding activity of ecalectin/galectin-9 for eosinophil chemoattraction. J Biol Chem 275: 8355-8360, 2000.

8. Matsumoto R, Hirashima M, Kita H and Gleich GJ: Biological activities of ecalectin: A novel eosinophil-activating factor. J Immunol 168: 1961-1967, 2002.

9. Saita N, Goto E, Yamamoto T, Cho I, Tsumori K, Kohrogi H, Maruo K, Ono T, Takeya M, Kashio Y, et al: Association of galectin-9 with eosinophil apoptosis. Int Arch Allergy Immunol 128: 42-50, 2002.

10. Asakura H, Kashio Y, Nakamura K, Seki M, Dai S, Shirato Y, Abedin MJ, Yoshida N, Nishi N, Imaizumi T, et al: Selective eosinophil adhesion to fibroblast via IFN-gamma-induced galectin-9. J Immunol 169: 5912-5918, 2002.

11. Dai SY, Nakagawa R, Itoh A, Murakami H, Kashio Y, Abe H, Katoh S, Kontani K, Kihara M, Zhang SL, et al: Galectin-9 induces maturation of human monocyte-derived dendritic cells. J Immunol 175: 2974-2981, 2005.

12. Nobumoto A, Oomizu S, Arikawa T, Katoh S, Nagahara K, Miyake M, Nishi N, Takeshita K, Niki T, Yamauchi A, et al: Galectin-9 expands unique macrophages exhibiting plasmacytoid dendritic cell-like phenotypes that activate NK cells in tumor-bearing mice. Clin Immunol 130: 322-330, 2009.

13. Wiersma VR, de Bruyn M, Helfrich W and Bremer E: Therapeutic potential of Galectin-9 in human disease. Med Res Rev 33 (Suppl 1): E102-E126, 2013.

14. Fujihara S, Mori H, Kobara H, Rafiq K, Niki T, Hirashima M and Masaki T: Galectin-9 in cancer therapy. Recent Pat Endocr Metab Immune Drug Discov 7: 130-137, 2013.

15. Kashio Y, Nakamura K, Abedin MJ, Seki M, Nishi N, Yoshida N, Nakamura T and Hirashima M: Galectin-9 induces apoptosis through the calcium-calpain-caspase-1 pathway. J Immunol 170: 3631-3636, 2003.

16. Lu LH, Nakagawa R, Kashio Y, Ito A, Shoji H, Nishi N, Hirashima M, Yamauchi A and Nakamura T: Characterization of galectin-9-induced death of Jurkat T cells. J Biochem 141: $157-172,2007$.

17. Kobayashi T, Kuroda J, Ashihara E, Oomizu S, Terui Y, Taniyama A, Adachi S, Takagi T, Yamamoto M, Sasaki N, et al: Galectin-9 exhibits anti-myeloma activity through JNK and p38 MAP kinase pathways. Leukemia 24: 843-850, 2010.

18. Kuroda J, Yamamoto M, Nagoshi H, Kobayashi T, Sasaki N, Shimura Y, Horiike S, Kimura S, Yamauchi A, Hirashima M, et al: Targeting activating transcription factor 3 by Galectin-9 induces apoptosis and overcomes various types of treatment resistance in chronic myelogenous leukemia. Mol Cancer Res 8: 994-1001, 2010. 
19. Kageshita T, Kashio Y, Yamauchi A, Seki M, Abedin MJ, Nishi N Shoji H, Nakamura T, Ono T and Hirashima M: Possible role of galectin-9 in cell aggregation and apoptosis of human melanoma cell lines and its clinical significance. Int J Cancer 99: 809-816, 2002.

20. Wiersma VR, de Bruyn M, van Ginkel RJ, Sigar E, Hirashima M, Niki T, Nishi N, Samplonius DF, Helfrich W and Bremer E: The glycan-binding protein galectin-9 has direct apoptotic activity toward melanoma cells. J Invest Dermatol 132: 2302-2305, 2012.

21. Fujita K, Iwama H, Sakamoto T, Okura R, Kobayashi K, Takano J, Katsura A, Tatsuta M, Maeda E, Mimura S, et al: Galectin-9 suppresses the growth of hepatocellular carcinoma via apoptosis in vitro and in vivo. Int J Oncol 46: 2419-2430, 2015.

22. Kobayashi K, Morishita A, Iwama H, Fujita K, Okura R, Fujihara S, Yamashita T, Fujimori T, Kato K, Kamada H, et al: Galectin-9 suppresses cholangiocarcinoma cell proliferation by inducing apoptosis but not cell cycle arrest. Oncol Rep 34: 1761-1770, 2015.

23. Tadokoro T, Morishita A, Fujihara S, Iwama H, Niki T, Fujita K, Akashi E, Mimura S, Oura K, Sakamoto T, et al: Galectin-9: An anticancer molecule for gallbladder carcinoma. Int J Oncol 48: $1165-1174,2016$

24. Nishi N, Itoh A, Fujiyama A, Yoshida N, Araya S, Hirashima M, Shoji $\mathrm{H}$ and Nakamura T: Development of highly stable galectins: Truncation of the linker peptide confers proteaseresistance on tandem-repeat type galectins. FEBS Lett 579: 2058-2064, 2005.

25. Schutte B, Henfling M, Kölgen W, Bouman M, Meex S, Leers MP, Nap M, Björklund V, Björklund P, Björklund B, et al: Keratin $8 / 18$ breakdown and reorganization during apoptosis. Exp Cell Res 297: 11-26, 2004.

26. Laemmli UK: Cleavage of structural proteins during the assembly of the head of bacteriophage T4. Nature 227: 680-685, 1970.

27. Towbin H, Staehelin T and Gordon J: Electrophoretic transfer of proteins from polyacrylamide gels to nitrocellulose sheets: Procedure and some applications. Proc Natl Acad Sci USA 76: 4350-4354, 1979.

28. Irie A, Yamauchi A, Kontani K, Kihara M, Liu D, Shirato Y, Seki M, Nishi N, Nakamura T, Yokomise H, et al: Galectin-9 as a prognostic factor with antimetastatic potential in breast cancer. Clin Cancer Res 11: 2962-2968, 2005.
29. Kramer G, Erdal H, Mertens HJ, Nap M, Mauermann J, Steiner G, Marberger M, Bivén K, Shoshan MC and Linder S: Differentiation between cell death modes using measurements of different soluble forms of extracellular cytokeratin 18. Cancer Res 64: 1751-1756, 2004.

30. Wiersma VR, de Bruyn M, Wei Y, van Ginkel RJ, Hirashima M, Niki T, Nishi N, Zhou J, Pouwels SD, Samplonius DF, et al: The epithelial polarity regulator LGALS9/galectin-9 induces fatal frustrated autophagy in KRAS mutant colon carcinoma that depends on elevated basal autophagic flux. Autophagy 11: 1373-1388, 2015.

31. Takano J, Morishita A, Fujihara S, Iwama H, Kokado F, Fujikawa K, Fujita K, Chiyo T, Tadokoro T, Sakamoto T, et al: Galectin-9 suppresses the proliferation of gastric cancer cells in vitro. Oncol Rep 35: 851-860, 2016.

32. Fulda S: Targeting apoptosis for anticancer therapy. Semin Cancer Biol 31: 84-88, 2015.

33. Waugh DJ and Wilson C: The interleukin-8 pathway in cancer. Clin Cancer Res 14: 6735-6741, 2008.

34. Ogura M, Takeuchi H, Kawakubo H, Nishi T, Fukuda K, Nakamura R, Takahashi T, Wada N, Saikawa Y, Omori T, et al: Clinical significance of CXCL-8/CXCR-2 network in esophageal squamous cell carcinoma. Surgery 154: 512-520, 2013.

35. Ladeiro Y, Couchy G, Balabaud C, Bioulac-Sage P, Pelletier L, Rebouissou S and Zucman-Rossi J: MicroRNA profiling in hepatocellular tumors is associated with clinical features and oncogene/tumor suppressor gene mutations. Hepatology 47: 1955-1963, 2008

36. Iorio MV, Visone R, Di Leva G, Donati V, Petrocca F, Casalini P, Taccioli C, Volinia S, Liu CG, Alder H, et al: MicroRNA signatures in human ovarian cancer. Cancer Res 67: 8699-8707, 2007.

37. Tanaka K, Miyata H, Yamasaki M, Sugimura K, Takahashi T, Kurokawa Y, Nakajima K, Takiguchi S, Mori M and Doki Y: Circulating miR-200c levels significantly predict response to chemotherapy and prognosis of patients undergoing neoadjuvant chemotherapy for esophageal cancer. Ann Surg Oncol 20 (Suppl 3): S607-S615, 2013.

38. Hamano R, Miyata H, Yamasaki M, Kurokawa Y, Hara J, Moon JH, Nakajima K, Takiguchi S, Fujiwara Y, Mori M, et al: Overexpression of miR-200c induces chemoresistance in esophageal cancers mediated through activation of the Akt signaling pathway. Clin Cancer Res 17: 3029-3038, 2011 